\title{
BMJ Open Opioid prescribing for chronic musculoskeletal pain in UK primary care: results from a cohort analysis of the COPERS trial
}

\author{
Tomi Ashaye, ${ }^{1}$ Natalia Hounsome, ${ }^{2}$ Dawn Carnes, ${ }^{2}$ Stephanie J C Taylor, ${ }^{2}$ \\ Kate Homer, ${ }^{2}$ Sandra Eldridge, ${ }^{2}$ Anne Spencer, ${ }^{3}$ Anisur Rahman, ${ }^{4}$ Jens Foell, ${ }^{2}$ \\ Martin R Underwood, ${ }^{5}$ on behalf of the COPERS Study Team (ISRCTN 24426731).
}

To cite: Ashaye T, Hounsome N, Carnes D, et al. Opioid prescribing for chronic musculoskeletal pain in UK primary care: results from a cohort analysis of the COPERS trial. BMJ Open 2018;8:e019491. doi:10.1136/ bmjopen-2017-019491

- Prepublication history and additional material for this paper are available online. To view these files, please visit the journal online (http://dx.doi. org/10.1136/bmjopen-2017019491).

Received 6 September 2017 Revised 24 January 2018 Accepted 26 January 2018

Check for updates

${ }^{1}$ Barts and The London School of Medicine and Dentistry, Queen Mary University of London, London, UK

${ }^{2}$ Centre for Primary Care and Public Health, Queen Mary University of London, London, UK

${ }^{3}$ Exeter Medical School, University of Exeter, Exeter, Devon, UK

${ }^{4}$ Centre for Rheumatology Research, University College London, London, UK

${ }^{5}$ Clinical Trials Unit, Warwick Medical School, University of Warwick, Coventry, UK

Correspondence to

Dr. Natalia Hounsome; n.hounsome@bsms.ac.uk

\section{ABSTRACT}

Objective To establish the level of opioid prescribing for patients with chronic musculoskeletal pain in a sample of patients from primary care and to estimate prescription costs.

Design Secondary data analyses from a two-arm pragmatic randomised controlled trial (COPERS) testing the effectiveness of group self-management course and usual care against relaxation and usual care for patients with chronic musculoskeletal pain (ISRCTN 24426731).

Setting 25 general practices and two community musculoskeletal services in the UK (London and Midlands).

Participants 703 chronic pain participants; $81 \%$ white, $67 \%$ female, enrolled in the COPERS trial.

Main outcome measures Anonymised prescribing data over 12 months extracted from GP electronic records. Results of the 703 trial participants with chronic musculoskeletal pain, $413(59 \%)$ patients were prescribed opioids. Among those prescribed an opioid, the number of opioid prescriptions varied from 1 to 52 per year. A total of 3319 opioid prescriptions were issued over the study period, of which 53\% (1768/3319) were for strong opioids (tramadol, buprenorphine, morphine, oxycodone, fentanyl and tapentadol). The mean number of opioid prescriptions per patient prescribed any opioid was $8.0(\mathrm{SD}=7.9)$. A third of patients on opioids were prescribed more than one type of opioid; the most frequent combinations were: codeine plus tramadol and codeine plus morphine. The cost of opioid prescriptions per patient per year varied from $£ 3$ to $£ 4844$. The average annual prescription cost was $£ 24$ ( $S D=29)$ for patients prescribed weak opioids and $£ 174$ ( $S D=421)$ for patients prescribed strong opioids. Approximately $40 \%$ of patients received $>3$ prescriptions of strong opioids per year, with an annual cost of $£ 236$ per person.

Conclusions Long-term prescribing of opioids for chronic musculoskeletal pain is common in primary care. For over a quarter of patients receiving strong opioids, these drugs may have been overprescribed according to national guidelines.

Trial registration number ISRCTN24426731; Postresults.
Strengths and limitations of this study

- This study focuses on the economic aspects of prescribing opioids in primary care.

- This study uses individual patient-level data to quantify opioid prescribing for people with musculoskeletal pain.

- This study looks at the coprescribing of opioids in primary care.

- This study does not look at longitudinal changes in prescribing opioids to patients with chronic musculoskeletal pain.

- This study does not attempt to relate opioid prescriptions with treatment effectiveness.

\section{INTRODUCTION}

'Few things a doctor does are more important than relieving pain ... pain is soul destroying. ${ }^{1}$ These words from Marcia Angell, former editor in chief of the New England Medical Journal, succinctly illustrate the therapeutic need for pain relief. However, prescribers have to balance both benefits and harm to patients from pharmacological treatment. Untreated pain can cause both physical and mental distress. One in five people suffer from chronic pain, the most common sources being back pain $(24 \%)$ or osteoarthritis $(35 \%) .^{23}$ Findings from the Global Burden of Disease study highlight musculoskeletal conditions as the largest cause of disability in the UK. ${ }^{4}$ Pain is the main symptom of many musculoskeletal conditions and it is closely associated with depression, anxiety, fatigue and sleep deprivation. The WHO recognises chronic musculoskeletal pain as a global priority and aims to better alert nations to the health and economic costs brought about by musculoskeletal conditions. ${ }^{5}$

Opioids are a popular form of analgesia. Up to $90 \%$ of individuals presenting to pain 
centres receive opioids. ${ }^{6}$ There is a lack of evidence supporting the efficacy of opioids for chronic non-malignant pain management. Several studies have demonstrated that opioids achieve negligible improvements in pain, function and quality of life. ${ }^{7-10}$ In addition, as prescribed doses of opioids increase so does the risk of adverse effects such as depression, anxiety, headaches, insomnia, inadvertent overdose and death. ${ }^{11}$ According to a UK Office of National Statistics report, ${ }^{12}$ accidental drug overdose is rising, with the highest number recorded since comparable records began in 1993. Of the 3346 drug poisoning deaths registered in 2014, 53\% involved an opiate drug. ${ }^{12}$ The UK guidelines on chronic pain management for people with low back pain and osteoarthritis $^{13-16}$ recommend weak opioids as a second-line treatment when the first-line medication (non-steroidal anti-inflammatory drugs, paracetamol or cyclo-oxygenase-2 inhibitors) is ineffective or not tolerated. Strong opioids are to be only prescribed for unremitting cases and even then for short-term use only, stepping patients down to weaker opioids as appropriate, or removing altogether if not effective. ${ }^{15}$

In past years, there has been a range of publications from both media and the medical profession suggesting that prescribed opioid doses are too high and are prescribed for too long, actually endangering patients. ${ }^{17-19}$ An editorial in The BMJ entitled: 'Opioids in the UK: What is the problem? ${ }^{20}$ concisely summarised concerns from the growing qualitative literature on the overprescription of opioids for chronic non-malignant pain. There is a growing apprehension that the rise in drug-related deaths parallels a rise in opioid prescriptions. ${ }^{921-23}$ However, this is an argument based on evidence from the USA, where rising numbers of deaths have involved prescription drug overdoses. ${ }^{24-26}$ There are few reliable data on opioid prescriptions in the UK to infer whether overprescription is an issue.

In this study, our aim was to explore opioid prescribing in a sample of patients with chronic musculoskeletal pain in primary care and to estimate the associated costs. We conducted secondary analyses of prescription data from the COPERS trial: a randomised, multicentre, pragmatic trial of a non-pharmacological group intervention for people with chronic musculoskeletal pain conducted across 27 general practices and musculoskeletal services across the UK. ${ }^{27-29}$ We undertook a secondary analysis looking at the entire cohort of patients to characterise patterns of opioid prescription and to estimate the opioid prescription cost. We also looked at the regional differences in opioid prescribing between two UK geographical areas -London and the Midlands.

\section{METHODS}

\section{Data sources and study characteristics}

We used an anonymised database from the COPERS trial that contained the prescription data for the 703 participants. Study design, setting and participants' characteristics are described in detail elsewhere. ${ }^{28}{ }^{29}$ Briefly, COPERS was a multicentre, pragmatic, randomised controlled effectiveness and cost-effectiveness trial conducted in the UK from 2011 to 2012. Seven hundred and three adults with musculoskeletal pain were randomised using a ratio 1.33:1 to intervention $(n=403)$ or control $(n=300)$. In the intervention group, the participants had usual care and were offered a group self-management intervention using cognitive behavioural approaches for the non-pharmacological management of chronic pain (the COPERS course). The primary outcome was pain-related disability at 12 months (Chronic Pain Grade disability subscale). There was a wide range of secondary outcome measures which included the Hospital Anxiety and Depression Scale, healthcare resource use and EQ-5D-3L. Healthcare resource use data included information on the number of contacts with primary and secondary healthcare services, and prescribing data which were collected from participants' GP electronic records at 12 months. The study did not find any significant differences in prescribing opioids between the intervention and control groups. No serious adverse events (related or not related to opioid use) were reported in either arm of the trial. ${ }^{29}$ We therefore conducted cohort analyses using data for both groups to characterise opioid prescribing for people with chronic musculoskeletal pain.

\section{Participants}

The characteristics of study participants and recruitment procedures are described elsewhere. ${ }^{27}$ Briefly, participants were adults ( $\geq 18$ years) with musculoskeletal pain of at least 3 months' duration. Causes of pain included, but were not restricted to: osteoarthritis, back pain, chronic widespread pain and fibromyalgia. Participants were recruited in the UK (London and the Midlands) from primary care, community musculoskeletal pain services and secondary care pain services. Exclusion criteria were: inability to give informed consent, not fluent in English, chronic pain arising from active malignant disease or inflammatory arthritis, terminal illness, or serious uncontrolled mental health or substance abuse preventing individuals from participating in the group sessions. The demography of the study participants was: $67 \%$ female, mean age 60 years ( 52 years in London and 67 in Midlands) and $81 \%$ white British.

\section{Prescription analysis}

We extracted and anonymised prescribing data over 12 months from participants' GP electronic records. The data set included information on: formulation, dose/ strength and the number of prescription items for each participant. A 'prescription' refers to a single medicine prescribed by a doctor on a prescription form. The data set contained 40649 prescriptions in total; these included other items as well as opioids. Opioids were identified in the data set by their generic (non-proprietary) names using the British National Formulary classification system. ${ }^{30}$ Searches were conducted for strong 


\begin{tabular}{|c|c|c|c|}
\hline Opioid & $\begin{array}{l}\text { Number of } \\
\text { prescriptions }\end{array}$ & Cost (£) & $\begin{array}{l}\text { Average cost per } \\
\text { prescription }(£)\end{array}$ \\
\hline Buprenorphine & 391 & 14204 & 36 \\
\hline $\begin{array}{l}\text { Codeine/ } \\
\text { dihydrocodeine }\end{array}$ & 1551 & 6899 & 4 \\
\hline Fentanyl & 41 & 2024 & 49 \\
\hline Morphine & 288 & 3658 & 13 \\
\hline Oxycodone & 183 & 11484 & 63 \\
\hline Tapentadol & 9 & 356 & 40 \\
\hline Tramadol & 856 & 5864 & 7 \\
\hline Total & 3319 & 44491 & 30 \\
\hline
\end{tabular}

opioids (buprenorphine, diamorphine, dipipanone, fentanyl, morphine, oxycodone, papaveretum, pentazocine, pethidine, tapentadol and tramadol) and weak opioids (codeine, dihydrocodeine and meptazinol). We also searched for combination formulations which contained weak opioids: co-codamol (codeine phosphate/paracetamol) and co-dydramol (dihydrocodeine/ paracetamol). The searches were conducted using wildcards and the VLOOKUP option in Microsoft Excel. The multivariate analysis of variance (MANOVA) was conducted using IBM SPSS Statistics V.22. The cost of opioid prescriptions was calculated using the Prescription Cost Analysis 2012 database $^{31}$ using a net ingredient cost per item (cost without discount and dispensing fees per single item prescribed on a prescription form). The list of costs used in the study is shown in online supplementary appendix 1. We did not compare oral morphine equivalent doses due to lack of consistency in the conversion ratios taken from different sources. ${ }^{32-34}$

\section{RESULTS}

For the 703 study participants, 413 (59\%) were prescribed opioids. In total, 3319 opioid prescriptions were issued over the 12-month period, of which 53\% (1768/3319) were for strong opioids (tramadol, buprenorphine, morphine, oxycodone, fentanyl and tapentadol). The number of opioid prescriptions varied from 1 to 52 per person per year. The average number of opioid prescriptions per patient was $8.0(\mathrm{SD}=7.9)$. Table 1 shows the annual numbers of opioid prescriptions and their costs. The cost per prescription varied from $£ 4$ to $£ 63$ with oxycodone being the most costly opioid prescription. The overall cost of all prescribed opioids during the 12 -month study period was $£ 44491$ (on average $£ 63.29$ per participant).

Figure 1 shows the proportions of prescribed opioids. Oral opioids comprised $86.9 \%$, transdermal $13.0 \%$ and parenteral $0.1 \%$ of all opioids prescribed. The most frequently prescribed opioid was codeine $(47 \%)$, which also included combination formulations co-codamol

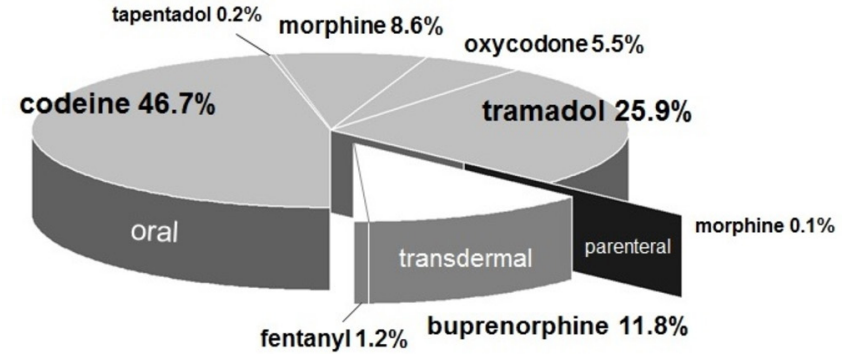

Figure 1 Proportional distribution of opioid prescriptions in the overall cohort of patients.

(codeine phosphate/paracetamol) and co-dydramol (dihydrocodeine/paracetamol). Tramadol was the most frequently prescribed strong opioid $(26 \%)$, followed by buprenorphine $(12 \%)$, morphine $(9 \%)$ and oxycodone $(6 \%)$. Parenteral morphine was prescribed to one patient only, although we do know whether this was for chronic pain or for acute pain management. Figure 2 illustrates the coprescribing of different types of opioids in the cohort of patients with chronic musculoskeletal pain. A combination of opioids was prescribed to $32 \%(132 / 413)$ of patients. Among these, 112 (27\%) people received two different types of opioids, $17(4 \%)$ three types, and 3 people $(1 \%)$ were prescribed more than three types of opioids. The most frequent combination of opioids was codeine plus tramadol (83 people), followed by codeine plus morphine (19 people), codeine plus buprenorphine (19 people) and morphine plus tramadol (15 people).

Table 2 summarises numbers of people prescribed different types of opioids in the entire cohort and in the two samples (London and the Midlands). The proportion of people with musculoskeletal pain prescribed opioids was higher in the Midlands sample (63\%) compared with the London sample (56\%). Morphine was more frequently prescribed in the Midlands (10\%) compared with London (3.7\%). The average number of opioid prescriptions per patient was also higher in the Midlands sample 8.58 (SD 8.12) compared with the London sample 7.33 (SD 7.56), although this difference was not statistically significant. The proportions of patients receiving different combinations of opioids were similar in the London and the Midland samples. MANOVA tests conducted using prescription numbers for different types of opioids showed no significant differences between London and Midlands samples ( $p>0.05$, not shown).

Table 3 summarises prescription characteristics for people receiving weak and strong opioids. More than half of these patients $(56 \%, 231 / 413)$ were prescribed strong opioids. Patients taking strong opioids received on average 10 prescriptions per year with an annual cost of $£ 174$ per patient. Among these people, $40 \%$ received $>3$ strong opioid prescriptions per year, costing on average $£ 236$ per person. Patients taking weak opioids received on average five prescriptions a year with an annual cost of £24 per person. Within this group, $21 \%$ of people received $>3$ prescriptions per year costing on average $£ 40$ per person. 


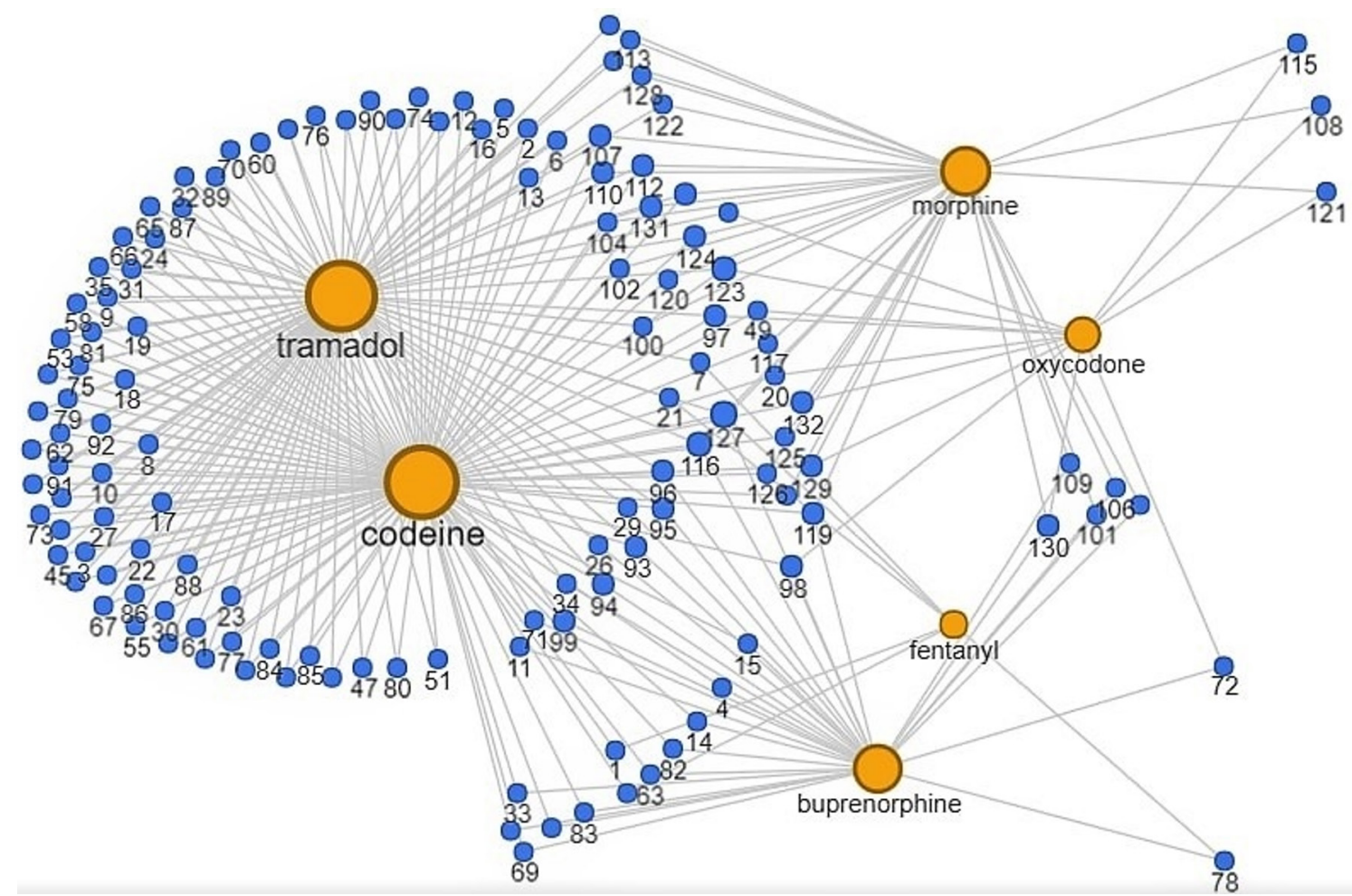

Figure 2 Network plot showing coprescribing of opioids for 132 patients. Patients are indicated by blue circles with numbers, which are linked to prescribed opioids (yellow circles). The size of the circles is proportional to the number of prescribed opioids.

Table 2 Number of study participants prescribed opioids and the average number of prescriptions in different samples

\begin{tabular}{|c|c|c|c|c|c|c|}
\hline \multirow{2}{*}{$\begin{array}{l}\text { Prescription } \\
\text { characteristics }\end{array}$} & \multicolumn{2}{|c|}{ London $(n=320)$} & \multicolumn{2}{|c|}{ Midlands ( $n=383$ ) } & \multicolumn{2}{|c|}{ Full sample $(n=703)$} \\
\hline & $\mathbf{n}$ & $\%$ & $\mathbf{n}$ & $\%$ & $\mathbf{n}$ & $\%$ \\
\hline Prescribed opioids & 180 & 56 & 233 & 61 & 413 & 59 \\
\hline Buprenorphine & 21 & 6.6 & 24 & 6.3 & 45 & 6.4 \\
\hline Codeine & 130 & 40.6 & 150 & 39.2 & 280 & 39.8 \\
\hline Fentanyl & 5 & 1.6 & 3 & 0.8 & 8 & 1.1 \\
\hline Morphine & 9 & 2.8 & 35 & 9.1 & 44 & 6.3 \\
\hline Oxycodone & 6 & 1.9 & 9 & 2.3 & 15 & 2.1 \\
\hline Tapentadol & 0 & 0.0 & 1 & 0.3 & 1 & 0.1 \\
\hline Tramadol & 71 & 22.2 & 96 & 25.1 & 167 & 23.8 \\
\hline Single opioid & 126 & 39.4 & 163 & 42.6 & 289 & 41.1 \\
\hline Combination of opioids & 54 & 16.9 & 70 & 18.3 & 124 & 17.6 \\
\hline 2 opioids & 48 & 15.0 & 57 & 14.9 & 105 & 14.9 \\
\hline 3 opioids & 6 & 3.3 & 11 & 4.6 & 16 & 2.3 \\
\hline 4 opioids & 0 & 0 & 2 & 0.8 & 2 & 0.5 \\
\hline 5 opioids & 1 & 0.6 & 0 & 0 & 1 & 0.2 \\
\hline $\begin{array}{l}\text { Average number of } \\
\text { opioid prescriptions over } \\
12 \text { months }\end{array}$ & \multicolumn{2}{|c|}{$7.3(\mathrm{SD}=7.6)$} & \multicolumn{2}{|c|}{$8.6(\mathrm{SD}=8.1)$} & \multicolumn{2}{|c|}{$8.0(\mathrm{SD}=7.9)$} \\
\hline
\end{tabular}

\section{DISCUSSION}

In this study, we characterised opioid prescribing in a sample of people with chronic musculoskeletal pain recruited from primary care into a trial of a self-management intervention. Opioids were prescribed to $59 \%$ of study participants and $53 \%$ of these prescriptions were for strong opioids, indicating their frequent prescription for patients with chronic musculoskeletal 
pain. These strong opioids included tramadol (26\%), buprenorphine $(12 \%)$, morphine $(9 \%)$ and oxycodone (6\%). Approximately $40 \%$ of patients received $>3$ strong opioid prescriptions per year, suggesting long-term prescribing of strong opioids in primary care. According to the national guidelines on chronic pain management for people with low back pain and osteoarthritis, ${ }^{15} 16$ strong opioids are to be only prescribed in unremitting cases for short-term use, stepping down to weaker opioids, or removing altogether if not effective. ${ }^{15}$

Currently, there is no accepted definition of overprescribing. The use of this term largely depends on context; it can refer to unnecessary prescription, lack of clinical effectiveness or side effects. ${ }^{35-37}$ In opioid studies, overprescription is closely associated with opioid misuse and abuse. ${ }^{9} 38{ }^{39}$ Dunn et at analysed the relationship between prescribed opioid doses and the risk of overdose in 9940 patients with chronic non-malignant pain. People receiving daily oral morphine equivalent doses in the range of $50-99 \mathrm{mg}$ have a 3.7 -fold increase in overdose risk, while patients receiving doses of $100 \mathrm{mg}$ or more had an 8.9-fold increase in overdose risk compared with patients prescribed $<20 \mathrm{mg} /$ day. ${ }^{9}$ Given that opioids differ in their potency, formulation and administration routes, converting opioid doses to oral morphine would be one way of identifying the overprescription of opioids. However, there are differences in the conversion ratios to oral morphine used in the national guidelines and formularies. ${ }^{32-34}$ There is also individual variation in patient response to opioids in terms of metabolism, distribution and receptor dynamics. ${ }^{40}{ }^{41}$ Therefore, opioid conversion ratios are purely guidelines that provide starting points for switching between different opioids for the majority of individuals, subject to further assessment and dose titration.

In the context of this study, overprescribing can be defined as the long-term prescribing of strong opioids ( $>3$ prescriptions a year). This is consistent with the National Institute for Health and Care Excellence guidelines for the most common painful conditions (low back pain and osteoarthritis), which recommend strong opioids to be prescribed for a short time only. ${ }^{1516}$ We found that $40 \%$ of patients receiving opioids for chronic musculoskeletal pain may be overprescribed. The estimated cost of overprescription was 2236 per person per year (table 3).
According to recent analyses of opioid prescribing in the UK primary care, $1.25-1.38$ million people with musculoskeletal conditions receive long-term opioids. ${ }^{42}$ Assuming that $40 \%$ of these people are overprescribed, the cost of opioid overprescription may be over $£ 100$ million/year. This does not include costs associated with the management of side effects and overdose. We were unable to calculate these costs since there were no opioid-related serious adverse events in either arm of the trial. ${ }^{29}$ The trial was not designed to capture non-serious adverse events associated with opioid use.

Although our understanding of chronic pain management has advanced, the effective treatment of chronic pain remains elusive. In the chronic pain management guidelines for Australia, Canada, Germany, USA and UK, weak opioids are considered a treatment option. ${ }^{15} 1643-45$ Opioids are used to treat both acute and chronic pain, despite pain experts being in agreement over their poor effectiveness for the latter. ${ }^{46-48}$ Some reports suggest that prescribing opioids for chronic pain may be associated with poorer functional outcomes (eg, disability, pain intensity, anxiety and depression) compared with other treatment strategies. ${ }^{49}{ }^{50}$ Since the late 1990 s, under growing public pressure and aggressive pharmaceutical marketing to eliminate pain, physicians globally have been ever more proactive in their efforts to identify and treat chronic pain. In the UK, the latest published data show that from 2005 to 2015 use of analgesics rose by 21 million items, increasing costs by $£ 230.1$ million. ${ }^{51}$ Among opioids, the increase in the number of prescribed items was $10.5 \%$ for oxycodone, $9.2 \%$ for morphine and $8.9 \%$ for buprenorphine..$^{51}$ Nevertheless, pain intensity does not improve in patients with chronic pain on higher compared with lower opioid doses, indicating poor efficiency in current opioid prescription practice. ${ }^{7-9}$ Scientific literature is flooded with information on the dangers of opioid misuse, abuse and addiction as a recreational drug. ${ }^{5-54}$ However, fatalities from recreational opioid misuse are now overshadowed by medically prescribed opioid-related deaths; in the USA, these accounts for $60 \%$ of opioid-related deaths, ${ }^{55}$ and data from the US National Center for Health Statistics show that opioid deaths have increased above that of the deaths from heroin and cocaine combined..$^{24}$ Physicians have raised the alarm about the rise in opioid prescribing in primary

Table 3 Characteristics of opioid prescriptions in patients receiving strong and weak opioids $(n=413)$

\begin{tabular}{lll}
\hline Prescription characteristics & $\begin{array}{l}\text { People receiving strong opioids } \\
\mathbf{n = 2 3 1}\end{array}$ & $\begin{array}{l}\text { People receiving weak opioids } \\
\mathbf{n = 1 8 2}\end{array}$ \\
\hline Number of patients prescribed opioids & $231(56 \%)$ & $182(44 \%)$ \\
\hline Annual number of prescriptions & 2332 & 987 \\
Annual cost per patient & $£ 174$ & $£ 24$ \\
\hline $\begin{array}{l}\text { Average number of prescriptions a year (SD) } \\
\text { Number of patients receiving }>3 \text { prescriptions a year }\end{array}$ & $10(9)$ & $5(5)$ \\
\hline $\begin{array}{l}\text { Average cost per patient receiving }>\text { 3 prescriptions a } \\
\text { year }\end{array}$ & $£ 236$ & $88(21 \%)$ \\
\hline
\end{tabular}


care, saying that in many cases doses are too high and treatments are too long. ${ }^{17-19}{ }^{56}$ Current guidelines for the management of conditions associated with chronic pain ${ }^{14-16}$ reiterate importance of maintaining physical activity, physiotherapy and education programmes. In recent decades, a more holistic approach to chronic pain management has been taken. New treatments involve self-management, coping strategies such as distraction or relaxation techniques, and lower doses of pain relief medication. ${ }^{57} 58$ The purpose of chronic musculoskeletal pain management is to enable the individual to live with the pain, yet limit its impact on their daily functioning, consistent with a biopsychosocial model of health. ${ }^{59}$ The cost-effectiveness of these therapies is yet to be established. The study of a non-pharmacological intervention for people with chronic musculoskeletal pain, which generated data for this manuscript, did not find any significant effect on pain severity. ${ }^{28}{ }^{29}$ However, the intervention was found to be cost-effective due to a reduction in depression and an improvement in health-related quality of life. ${ }^{28}{ }^{29}$ Researchers recognise the importance of assessing multiple outcomes in pain management studies and that research in pain management should go beyond comparing the clinical effectiveness of different treatments, but address questions of "what treatment is effective, for which patients, on what outcomes, under what circumstances, and at what cost' ${ }^{60}$

\section{LIMITATIONS}

This study provides a snapshot of opioid prescribing in primary care over a period of 1 year; it did not look at longitudinal changes in prescribing opioids to patients with chronic musculoskeletal pain.

This study focused on the economic aspects of opioid prescribing; it did not attempt to relate opioid prescriptions with treatment effectiveness.

Our analysis assumes that all opioid prescriptions were for chronic pain and not for acute pain episodes.

\section{CONCLUSIONS}

Long-term prescribing of opioids for chronic musculoskeletal pain is common in primary care. For over a quarter of patients receiving strong opioids, these drugs may have been overprescribed according to national guidelines. The estimated cost of overprescribing opioids in UK primary care may be around $£ 100$ million/year.

Contributors TA and NH jointly conducted data analysis, wrote the first draft and integrated comments from the coauthors. DC, SJCT, KH, SE, AS, AR, JF and MRU critically revised the manuscript and provided methodological input. $\mathrm{NH}$ led data analyses and manuscript production. MRU and SJCT were the principal investigators on the COPERS project. DC, SE, AS and AR were coapplicants on the funding application. All coauthors contributed to the concept of the paper.

Funding This paper presents independent research commissioned by the National Institute for Health Research (NIHR) under its Programme Grants for Applied Research scheme (RP-PG-0707-10189).
Disclaimer The views expressed in this publication are those of the authors and not necessarily those of the NHS, the NIHR or the Department of Health.

Competing interests TA, NH, DC, SJCT, KH, SE, AS, AR and JF have no competing interests with relation to this paper. MRU is an applicant and coapplicant on multiple studies on pain funded by NIHR and ARUK. These include the I-WOTCH trial of opioid reduction 14/224/04 ISRCTN 49470934. He is an editor for the NIHR journal series for which he receives a fee. He is a director and shareholder of Clinvivo.

Patient consent Not required.

Ethics approval Cambridgeshire Ethics Committee provided a favourable ethical review for this study (Ref 11/EE/046).

Provenance and peer review Not commissioned; externally peer reviewed. Data sharing statement No additional data available.

Open Access This is an Open Access article distributed in accordance with the Creative Commons Attribution Non Commercial (CC BY-NC 4.0) license, which permits others to distribute, remix, adapt, build upon this work non-commercially, and license their derivative works on different terms, provided the original work is properly cited and the use is non-commercial. See: http://creativecommons.org/ licenses/by-nc/4.0/

(c) Article author(s) (or their employer(s) unless otherwise stated in the text of the article) 2018. All rights reserved. No commercial use is permitted unless otherwise expressly granted.

\section{REFERENCES}

1. Angell M. The quality of mercy. N Engl J Med 1982;306:98-9.

2. Fricker J. Pain in Europe -A 2003 Report, 2003. http://www.pae-eu. eu/wp-content/uploads/2013/12/Pain-in-Europe-survey-report.pdf. (accessed 7 Jul 2017).

3. Breivik H, Collett B, Ventafridda V, et al. Survey of chronic pain in Europe: prevalence, impact on daily life, and treatment. Eur J Pain 2006;10:287-333.

4. Murray CJ, Richards MA, Newton JN, et al. UK health performance: findings of the Global Burden of Disease Study 2010. Lancet 2013;381:997-1020.

5. WHO. Burden of Musculoskeletal Conditions at the Start of the New Millennium. Geneva: World Health Organization, 2003.

6. Trescot A, Glaser SE, Hansen H, et al. Effectiveness of opioids in the treatment of chronic non-cancer pain. Pain Physician 2008:2S:S181-S200.

7. Eriksen J, Sjøgren P, Bruera E, et al. Critical issues on opioids in chronic non-cancer pain:. Pain 2006;125:172-9.

8. Ballantyne JC, Shin NS. Efficacy of Opioids for Chronic Pain. Clin J Pain 2008:24:469-78.

9. Dunn KM, Saunders KW, Rutter CM, et al. Opioid prescriptions for chronic pain and overdose: a cohort study. Ann Intern Med 2010;152:85-92.

10. Noble M, Treadwell JR, Tregear SJ, et al. Long-term opioid management for chronic noncancer pain. Cochrane Database Syst Rev 2010;1:CD006605.

11. Rawal N. Management of acute and chronic pain. London: BMJ Books, 1998.

12. ONS (Office for National Statistics). Deaths related to drug poisoning in England and Wales, 2014 registrations. 1st ed: [eBook] ONS, 2014 http://www.ons.gov.uk/ons/dcp171778_414574.pdf. (accessed 7 Jul 2017).

13. The British Pain Society. Opioids for persistent pain: summary of guidance on good practice from the British Pain Society. $2010 \mathrm{http} / / /$ bjp.sagepub.com/content/6/1/9.full.pdf+html (accessed 7 Jul 2017).

14. The British Pain Society. Guidelines for Pain Management Programmes for adults. $2013 \mathrm{https} / / / \mathrm{www}$. britishpainsociety. org/static/uploads/resources/files/pmp2013_main_FINAL_v6.pdf (accessed 7 Jul 2017).

15. NICE (The National Institute for Health and Care Excellence). Osteoarthritis: care and management NICE guidelines CG177. 2014 https://www.nice.org.uk/guidance/cg177 (accessed 7 Jul 2017).

16. NICE (The National Institute for Health and Care Excellence) Low back pain and sciatica in over 16s: assessment and management. NICE guideline 59. 2016 https://www.nice.org.uk/guidance/ indevelopment/ng59/documents.

17. Von Korff M, Kolodny A, Deyo RA, et al. Long-term opioid therapy reconsidered. Ann Intern Med 2011;155:325-8.

18. Dhalla IA, Persaud N, Juurlink DN. Facing up to the prescription opioid crisis. BMJ 2011;343:d5142. 
19. Stannard C. Opioid prescribing in the UK: can we avert a public health disaster? Br J Pain 2012;6:7-8.

20. Stannard C. Opioids in the UK: what's the problem? BMJ 2013;347:f5108

21. Franklin GM, Mai J, Wickizer T, et al. Opioid dosing trends and mortality in Washington State workers' compensation, 1996-2002. Am J Ind Med 2005;48:91-9.

22. Braden JB, Russo J, Fan MY, et al. Emergency department visits among recipients of chronic opioid therapy. Arch Intern Med 2010;170:1425-32.

23. Bohnert AS, Valenstein M, Bair MJ, et al. Association between opioid prescribing patterns and opioid overdose-related deaths. JAMA 2011;305:1315-21.

24. Paulozzi LJ, Budnitz DS, Xi Y. Increasing deaths from opioid analgesics in the United States. Pharmacoepidemiol Drug Saf 2006;15:618-27.

25. Warner M, Chen LH, Makuc DM. Increase in fatal poisonings involving opioid analgesics in the United States, 1999-2006. NCHS Data Brief 2009;22:1-8.

26. Ray WA, Chung CP, Murray KT, et al. Prescription of Long-Acting Opioids and Mortality in Patients With Chronic Noncancer Pain. JAMA 2016;315:2415-23.

27. Carnes D, Taylor SJ, Homer K, et al. Effectiveness and costeffectiveness of a novel, group self-management course for adults with chronic musculoskeletal pain: study protocol for a multicentre, randomised controlled trial (COPERS). BMJ Open 2013;3:e002492.

28. Taylor SJ, Carnes D, Homer K, et al. Novel Three-Day, CommunityBased, Nonpharmacological Group Intervention for Chronic Musculoskeletal Pain (COPERS): A Randomised Clinical Trial. PLoS Med 2016;13:e1002040.

29. Taylor SJC, Carnes D, Homer K, et al. Improving the selfmanagement of chronic pain: COping with persistent Pain, Effectiveness Research in Self-management (COPERS. Southampton (UK): NIHR Journals Library. Programme Grants for Applied Research, 2016;4.

30. BNF (The British National Formulary) 4.7.2 Opioid analgesics. https:// www.evidence.nhs.uk/formulary/bnf/current/4-central-nervoussystem/47-analgesics/472-opioid-analgesics (accessed 7 Jul 2017).

31. NHS Digital. Prescription Cost Analysis England. $2012 \mathrm{http}: / /$ content. digital.nhs.uk/catalogue/PUB10610 (accessed 7 Jul 2017).

32. BNF. The British National Formulary). Pain management with opioids https://www.evidence.nhs.uk/formulary/bnf/current/guidance-onprescribing/prescribing-in-palliative-care/pain/pain-managementwith-opioids (accessed 7Jul 2017).

33. MIMS (Monthly Index of Medical Specialties) Opioid Analgesics: Approximate Potency Equivalence with Oral Morphine. http://www. mims.co.uk/opioid-analgesics-approximate-potency-equivalenceoral-morphine/pain/article/1146201 (accessed 7Jul 2017).

34. RCoA (The Royal College of Anaesthetists). Dose Equivalent and Changing Opioids. http://www.rcoa.ac.uk/faculty-of-pain-medicine/ opioids-aware/structured-approach-to-prescribing/dose-equivalentsand-changing-opioids (accessed 7Jul 2017).

35. Bush A, Fleming L. Is asthma overdiagnosed? Arch Dis Child 2016;101:688-9.

36. Llor C, Bjerrum L. Antimicrobial resistance: risk associated with antibiotic overuse and initiatives to reduce the problem. Ther Adv Drug Saf 2014;5:229-41.

37. Verhoeven V, Lopez Hartmann M, Wens J, et al. Happy pills in nursing homes in Belgium: A cohort study to determine prescribing patterns and relation to fall risk. Journal of Clinical Gerontology and Geriatrics 2014;5:53-7.

38. Dasgupta N, Sanford C, Albert S, et al. Opioid Drug Overdoses: A Prescription for Harm and Potential for Prevention. Am J Lifestyle Med 2010;4:32-7.
39. Miller M, Barber CW, Leatherman S, et al. Prescription opioid duration of action and the risk of unintentional overdose among patients receiving opioid therapy. JAMA Intern Med 2015;175:608-15.

40. Somogyi AA, Barratt DT, Coller JK. Pharmacogenetics of opioids. Clin Pharmacol Ther 2007;81:429-44.

41. Drewes AM, Jensen RD, Nielsen LM, et al. Differences between opioids: pharmacological, experimental, clinical and economical perspectives. Br J Clin Pharmacol 2013;75:60-78.

42. Bedson J, Chen Y, Hayward RA, et al. Trends in long-term opioid prescribing in primary care patients with musculoskeletal conditions: an observational database study. Pain 2016;157:1525-31.

43. Chou R, Fanciullo GJ, Fine PG, et al. Clinical guidelines for the use of chronic opioid therapy in chronic noncancer pain. $J$ Pain 2009;10:113-30.

44. Furlan AD, Reardon R, Weppler C. National Opioid Use Guideline Group. Opioids for chronic noncancer pain: a new Canadian practice guideline. CMAJ 2010;182:923-30.

45. Häuser W, Schug S, Furlan AD. The opioid epidemic and national guidelines for opioid therapy for chronic noncancer pain: a perspective from different continents. Pain Rep 2017;2:e599.

46. Furlan AD, Sandoval JA, Mailis-Gagnon A, et al. Opioids for chronic noncancer pain: a meta-analysis of effectiveness and side effects. CMAJ 2006;174:1589-94.

47. Chapman CR, Lipschitz DL, Angst MS, et al. Opioid pharmacotherapy for chronic non-cancer pain in the United States: a research guideline for developing an evidence-base. J Pain 2010;11:807-29.

48. Deyo RA, Von Korff M, Duhrkoop D. Opioids for low back pain. BMJ 2015;350:g6380.

49. Ashworth J, Green DJ, Dunn KM, et al. Opioid use among low back pain patients in primary care: Is opioid prescription associated with disability at 6-month follow-up? Pain 2013;154:1038-44.

50. Green DJ, Bedson J, Blagojevic-Burwell M, et al. Factors associated with primary care prescription of opioids for joint pain. Eur J Pain 2013;17:234-44.

51. HSCIC (Health and Social Care Information Centre). Prescriptions Dispensed in the Community England 2005-2015. http://content. digital.nhs.uk/catalogue/PUB20664/pres-disp-com-eng-2005-15rep.pdf (accessed 7Jul 2017)

52. Gilson AM, Kreis PG. The burden of the nonmedical use of prescription opioid analgesics. Pain Med 2009;10 Suppl 2(suppl 2):S89-S100.

53. Guo L, Xu Y, Deng J, et al. Association Between Nonmedical Use of Prescription Drugs and Suicidal Behavior Among Adolescents. JAMA Pediatr 2016;170:971-8.

54. Novak SP, Håkansson A, Martinez-Raga J, et al. Nonmedical use of prescription drugs in the European Union. BMC Psychiatry 2016;16:274.

55. Manchikanti L, Helm S, Fellows B, et al. Opioid epidemic in the United States. Pain Physician 2012;15(3 Suppl):ES9-38.

56. Zin CS, Chen LC, Knaggs RD. Changes in trends and pattern of strong opioid prescribing in primary care. Eur $J$ Pain 2014;18:1343-51.

57. Adams N, Poole H, Richardson C. Psychological approaches to chronic pain management: part 1. J Clin Nurs 2006;15:290-300.

58. Chang KL, Fillingim R, Hurley RW, et al. Chronic pain management: nonpharmacological therapies for chronic pain. FP Essent 2015;432:21-6.

59. Turk DC, Wilson H, Swanson KS, eds. The biopsychosocial model of pain and pain management. New York: Cambridge University Press, 2011.

60. Turk DC, Wilson HD, Cahana A. Treatment of chronic non-cancer pain. Lancet 2011;377:2226-35. 